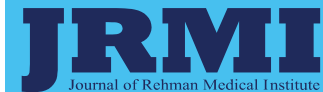

Volume 6, No. 3

July - September 2020 www.jrmi.pk

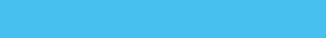

Submitted

September 15, 2020

Accepted

September 30, 2020

\section{Author Information}

Dr. Iftikhar Qayum Director Medical Research Rehman Medical College,

Peshawar, Khyber

Pakhtunkhwa, Pakistan

Email:

iftikhar.qayum@rmi.edu.pk

Citation: Qayum I. The

COVID-19 storm. [Editorial].

J Rehman Med Inst. 2020 Jul-

Sep;6(3):1-2.

\title{
The COVID-19 Storm
}

\section{Iftikhar Qayum}

\section{ABSTRACT}

A brief overview is presented of the global experience with the Novel Coronavirus 19 pandemic and disease (COVID-19) that produced an unanticipated and unprecedented storm in the global equilibrium. The pandemic is described as an external and internal storm, with resultant damage to global and personal health and lifestyles. The mechanisms and implications of the resulting crisis are also touched upon in brief.

The author declared no conflict of interest and agreed to be accountable for all aspects of the work.

\section{INTRODUCTION}

Though the world was not at peace, whatever claims of global serenity existed in December 2019 were shattered by a new storm arising from Wuhan, China, that outpaced and out-maneuvered the best of brains and resources that the world had to offer. And more so, because it was an invisible, if not invincible, storm, not the kind one associates with great gusts of wind, or dust, or waves of gushing water; rather it was a storm of the unseen, unheard of, barely alive, biological entity that we call a virus; and among them, an RNA retrovirus, not the strong DNA virus that we associate with many diseases. This type of virus is an expert in launching stealth attacks, gaining entry into the body through known cellular pathways and much like the fabled Trojan Horse of Troy, ${ }^{1}$ once inside, awakens to cause the havoc that befell many a kingdom of yore.

The storm took the shape of a Pandemic which still rages off and on, affecting almost the entire globe and causing many casualties of old, adult, and young alike. The world rushed to adopt preventive measures, much like had been done in previous pandemics, as there was no database of knowledge of how to deal with this new enemy. Laboratories sprang up to isolate, and decipher the viral genome, so that a counter attack could be launched, armed with that most crucial piece of information, the genetic code of the organism. Hasty plans were drawn up for possible strategies, a myriad of drugs were tried and found wanting, the rush for oxygen cylinders and respirators increased to a crescendo, and the futility of all efforts was apparent on all faces.

On the political and diplomatic fronts, new wars began with global leaders blaming each other for the outbreak and for causing its spread through inadequate preventive measures. The entire world took on a different outlook and life changed forever from previous fast-paced productive cycles to stay-at-home and work-from-home protocols. The economic havoc is yet to be measured as industries ground to a halt and commerce waned by the day. As the storm spread, hospitals ran out of beds and faced acute shortages of healthcare workers to provide support and relief to the multitude of sick clamoring for scant hospital space and resources.

Much more ominous though, was the storm within - the one that ravaged entire bodies leaving the victim slim chances of survival - reminiscent of the Darwinian concept of "survival of the fittest". This internal storm first took away the dear elders of families, later on depriving them of the infirm amongst them, yet later attacking the young and apparently healthy adults and youth of society. It appeared that it would wipe out entire generations if left to its own devices.

This internal storm was a biological marvel on its own. The attacker managed to convert the body's own sentinels, its soldiers and guards, against its own cells and tissues, so that now the enemy was twofold - the hordes of multiplying viruses, and the body's own immune system gone awry. It is a miracle that some people survived this internal storm as well, though most were swept away forever, or left incapacitated in some way. Labeled aptly as a "Cytokine Storm", it portrayed the power and potential of the indirectly unleashed havoc that the virus could cause, and left physicians and researchers at a loss to predict its occurrence or to treat it effectively.

The release of massive amounts of the body's most potent immune-mediating chemicals that were originally meant to destroy invaders produced unprecedented biochemical changes in the body which was powerless to defend itself against its own arsenal of chemical weapons. Thus, paradoxically and ironically, the very weapons that would normally be so sophisticated and effective against enemies had caused widespread irrecoverable damage to their own host after being hijacked by the foreign invaders

Briefly, as the virus invades different tissues, the locally present immune cells overreact and produce a multitudinous variety of cytokines to kill the virus (interferons, interleukins, chemokines, tumor necrosis factors, colony 
stimulating factors, and many more) ${ }^{2}$ in exaggerated fashion however, these same 'bullets' hit the innocent cell and tissue bystanders and like stray bullets cause immense destruction. Entry of virus into the lungs and other body areas signals the possibility of a subsequent cytokine storm in prone individuals.

The nature of biological mechanisms that invoke a cytokine storm is still being researched and the genomics of victims (mutations, polymorphisms found in immune reactive cells; cell signaling pathways; cytokine release mechanisms) are being unraveled to provide some level of predictability and possible preventive intervention. ${ }^{2}$ What is known about the cytokine storm however is that it tends to undergo a vicious cycle that continuously upgrades itself, thereby causing local and systemic injury and death of cells and tissues, ultimately leading to multiorgan and respiratory failure. ${ }^{2,3}$

It is also entirely possible, however, that the virus alters the dynamics and interactions of immune cells to the extent that their functions become abnormal. This scenario is very plausible, because viruses do integrate into cellular genomes and use their machinery to synthesize viral products, as well as cause genetic and epigenetic changes directed to their own benefit.

Based on our understanding of the molecular mechanisms involved in producing a cytokine storm, a host of therapeutic options have been developed to control it or obviate its local and systemic effects. Though some of these are effective, not all patients respond favorably, leading to the need for further research to unravel still hidden mechanisms and mediators.

The storm still rages on, coming back in waves, much like ocean tides, though with lesser ferocity as time goes by. Some of this is attributed to effective control by preventive and restrictive protocols that resulted in inspiring success stories like that of New Zealand and a few other nations. The hope offered by specific vaccines still outweighs all other measures, because they promise to afford once again the freedom to work in normal lifestyle routines. However the promise is yet to be seen or realized fully. For now, preventive precautions and hope for a better future will have to suffice.

\section{REFERENCES}

1. Trojan Horse. Wikipedia, the free 2. Tisoncik JR, Korth MJ, Simmons CP, Farrar encyclopedia. [Accessed 2020 September 12]. Available from: https://en.wikipedia.org/wiki/Trojan_Horse. 2012 Mar;76(1):16-32.
3. Ragab D, Eldin HS, Taeimah M, Khattab R, Salem R. The COVID-19 Cytokine Storm What We Know So Far. Front. Immunol. 2020 Jun 16;11:1446. doi 10.3389/fimmu.2020.01446 